\title{
Pai Tomás no romantismo brasileiro
}

\section{Hélio de Seixas Guimarães}

Resumo: A cabana do pai Tomás (1851-2), de Harriet Beecher Stowe, um dos grandes fenômenos literários do século XIX, teve repercussão significativa no meio literário brasileiro, conforme registros deixados por Macedo, Alencar, Bernardo Guimarães, Machado de Assis e Joaquim Nabuco. O artigo procura traçar os caminhos de chegada ao Brasil desse primeiro best-seller das Américas, que apenas em 1853 teve três traduções diferentes para o português, e seu impacto sobre as representações do escravo e da escravidão no Brasil. Palavras-chave: A cabana do pai Tomás, representação do escravo, romantismo brasileiro.

Abstract: The novel Uncle Tom's Cabin (1851-2), by Harriet Beecher Stowe, was one of the greatest literary phenomena in the $19^{\text {th }}$ Century, with a remarkable impact on the Brazilian literary milieu, as we learn from the testimonies of Joaquim Manuel de Macedo, José de Alencar, Bernardo Guimarães, Machado de Assis e Joaquim Nabuco. The article gives an account of the novel's translations into Portuguese - as early as 1853 there were three different translations already circulating in Portugal and Brazil - and of its reception in Brazil, where it had an important role in the literary representations of slaves and slavery. Keywords: Uncle Tom's Cabin, representation of the slave, Brazilian Romanticism. 
Joaquim Nabuco, ao revolver as memórias de infância em busca da gênese de sua simpatia para a questão abolicionista, escreveu em Minha formação, de 1900: "Mil vezes li a Cabana do pai Tomás, no original da dor vivida e sangrando". Dezessete anos antes, em O abolicionismo, Nabuco já se referira à mesma Cabana do pai Tomás. No seu livro de 1883 , escrevia que os sofrimentos reais dos escravos ultrapassavam em muito os verdadeiros martírios descritos nesse melodrama clássico, história de um escravo bondoso e profundamente cristão, o pai Tomás do título, que, vendido a um senhor cruel, aceita com resignação toda sorte de maus-tratos, passando por um calvário e um martírio que reencenavam calvário e martírio de Cristo.

A evocação do romance norte-americano mesclado às primeiras lembranças da escravidão dá a medida da profundidade das impressões que o livro da escritora norte-americana Harriet Beecher Stowe produziu sobre Nabuco, figura-chave do abolicionismo brasileiro, e também sobre uma geração inteira de intelectuais brasileiros que conviveram de perto com a escravidão. O depoimento de Nabuco também nos dá a medida do impacto que o romance teve para o abolicionismo brasileiro e nos faz pensar sobre o papel que teve nas representações do escravo e da escravidão nos textos produzidos no Brasil na segunda metade do século XIX.

A cabana do pai Tomás, originalmente publicado aos pedaços no jornal abolicionista The National Era, entre 1851 e 1852, foi um dos grandes fenômenos literários do século XIX. Lançado em livro em março de 1852, em Boston, nos Estados Unidos, a primeira edição de 5 mil exemplares esgotou-se em dois dias. Oito semanas depois, o livro havia vendido 50 mil exemplares, segundo dados publicados pela Biblioteca Pública de Nova York. No final de 1852, as vendas nos Estados Unidos chegaram a 300 mil exemplares. Na Grã-Bretanha, há notícias de quarenta edições pirateadas, que teriam somado mais de um milhão e meio de cópias. O livro foi traduzido para quarenta línguas, atingindo mais de 4 milhões de exemplares nos primeiros anos de circulação. Numa carta de junho de 1853, a autora descreveu o sucesso extraordinário do livro listando traduções para línguas tais como o valáquio (dialeto do romeno), o galês e o baixo-saxão holandês.

Na França, imediatamente ganhou várias traduções e provou reações extremas. Flaubert, por exemplo, mostrou-se profundamente incomodado com o romance. Flaubert trata do livro em duas cartas a Louise Colet, datadas de 22 de novembro e 9 de dezembro de 1852 . Na primeira, ainda sem haver lido o romance, diz ter um prejulgamento desfavorável ao livro, que acredita tocar apenas em paixões do momento (passions $d u$ jour). Na segunda prevê que o romance perderá sua efetividade quando não mais existirem escravos nos Estados Unidos, pois não serão mais verdadeiras 
as histórias antigas nas quais os muçulmanos são invariavelmente representados como monstros. Ainda nessa segunda carta, escreve o seguinte sobre a Cabana do pai Tomás:

As reflexões da autora me irritaram o tempo todo. É preciso fazer reflexão sobre a escravidão? Basta mostrá-la, e está feito. [...] Veja se há declamações contra a usura no Mercador de Veneza. A forma dramática tem essa vantagem, ela anula o autor. - Balzac não escapou do mesmo defeito, ele é legitimista, católico, aristocrata. - $\mathrm{O}$ autor deve estar em sua obra como Deus no universo: em toda parte, mas visível em parte alguma. ${ }^{1}$

O que incomodava Flaubert, sempre avesso à intromissão autoral no curso da narração, era o caráter sentimental e retórico do romance, repleto de perorações contra a instituição da escravidão.

Reação oposta teve Georges Sand, que escreveu, também em 1853, um artigo elogioso sobre o romance norte-americano, referido como "livro cheio de lágrimas, e de fogo", que "multiplicado por centenas de mil percorria os dois hemisférios arrancando lágrimas de todos os olhos que o liam". O artigo, publicado em La Presse, era a chancela de uma escritora consagrada na França para um sucesso popular que arrebatou e dividiu opiniões não só no mundo letrado francês, mas também no alemão e no inglês, e que muito em breve arrebataria também Portugal e Brasil.

O livro teve pelo menos três traduções para o português apenas no ano de 1853. A primeira, A cabana do pae Thomaz, ou os negros na America, foi publicada no Porto, em quatro volumes, numa tradução a partir do francês. Outra tradução portuguesa saiu no mesmo ano em Lisboa, com o título A cabana do tio Thomaz ou a vida dos negros na America, sem indicação do nome do tradutor, mas também a partir de uma tradução francesa. A terceira edição portuguesa de 1853 é A cabana do pai Thomaz ou a vida dos pretos na America: romance moral, traduzido a partir do inglês por Francisco Ladislau Álvares d'Andrada.

Nessa versão, vemos um tradutor consciente de que boa parte do seu leitor potencial estaria do lado de cá do Atlântico. Isso fica evidente numa nota em que, ao justificar a tradução da palavra "estate" por "engenho", o tradutor Francisco Ladislau explica: 
Como este meu trabalho é principalmente destinado para o Brasil, onde a admirável obra de Mrs. Stowe pode e deve ser mais apreciada que em parte alguma, adoptei os termos próprios daquele país, como, por exemplo, este d’engenho, que talvez algum leitor da Europa não saiba que quer dizer; em língua brasileira, fábrica onde se manipula o açúcar, e onde vive ordinariamente o senhor dela com os seus numerosos escravos. ${ }^{2}$

O tradutor também manifesta receio quanto ao desagrado que a obra poderia causar "nos países onde a escravatura existe, e onde ela é, e será talvez por muito tempo ainda um mal necessário". ${ }^{3}$ Ladislau termina o prefácio ponderando que a solução proposta por Stowe para a escravidão - o seu fim imediato - não pode ser aplicada ao Brasil e às colônias portuguesas, onde "o estado físico e moral" dos escravos não se pode comparar com o dos Estados Unidos e onde a extinção de semelhante flagelo poderia ferir "muitos outros interesses capitais". ${ }^{4}$

Francisco Ladislau tinha razão tanto no cálculo sobre onde estava o público da sua tradução como nos temores quanto à reação ao livro por parte desse público, amplamente escravista. Sabemos que a repercussão do Pai Tomás no Brasil foi intensa. Isso tanto no sentido de fornecer aos escritores daqui um estoque de imagens literárias do escravo e de situações relacionadas à escravidão, que passariam a integrar o imaginário dos escritores brasileiros (quantas das tragédias de ser vendido, dos sofrimentos da senzala, dos dramas familiares, das cenas de fuga e suicídio têm inspiração no livro de Beecher Stowe, que lhes deu figuração e ampla circulação internacional?), como nas reações de acolhimento e recusa que o livro provocou entre intelectuais e literatos brasileiros, que reagiram em suas obras às estratégias e procedimentos adotados por Beecher Stowe para defender a abolição da escravidão nos Estados Unidos. A presença do pai Tomás se multiplicou em traduções e adaptações da história que se sucederam, no Brasil e no mundo, não só na forma de livro, mas também em numerosas e célebres representações teatrais, que caprichavam na encenação dos suplícios dos escravos e viraram uma espécie de febre em todo o mundo, inclusive no Rio de Janeiro.

Em março de 1860, o jovem crítico Machado de Assis, ao escrever sobre a peça

A cabana do pai Thomaz ou a vida dos pretos na America. Romance moral. Escripto em inglez por Mrs. Harriet Beecher Stowe, e traduzido em portuguez por Francisco Ladislau Alvares d'Andrada. Em 2 tomos. Paris, Rey \& Belhatte, mercadores de livros, Quais des Augustins, 45, 1853, p. 33.

3 Idem, p.xvii.

4 Idem, p. xviii. 
Mãe, de José de Alencar, evocava pela primeira vez o nome de Stowe: "Esse drama, essencialmente nosso, podia, se outro fosse o entusiasmo de nossa terra, ter a mesma nomeada que o romance de Harriette [sic] Stowe, fundado no mesmo teatro da escravidão".

Na peça de Alencar, uma escrava dá à luz um filho, chamado Jorge, que se torna seu senhor, obviamente ignorando que a escrava é sua mãe. Necessitado de dinheiro para acudir o pai da mulher que pretende desposar, Jorge apela para um último recurso: vender a escrava, para tirar o futuro sogro de dificuldades financeiras. Na transação, revela-se o segredo da maternidade, criando-se um empecilho para a realização do casamento de Jorge com Elisa (é esse o nome da futura esposa), já que o fato de ele ser filho de escrava desagrada ao futuro sogro. No leito de morte, o filho reconhece a mãe, mas é tarde demais.

Alencar trabalha em diapasão parecido com o do romance norte-americano, sentimentalizando o tema da escravidão, que aparece conjugado com sentimentos de abnegação e sacrifício associados ao amor materno. Ele reedita o dilaceramento da separação entre mãe e filho, uma das cenas da escravidão que Beecher Stowe ajudou a popularizar com seu romance, que também deu enorme visibilidade aos castigos corporais dos escravos, que passaram a circular amplamente na produção ficcional que tematiza a escravidão, em que cenas de açoitamento, que a princípio tanto escandalizaram o público norte-americano, tornaram-se quase obrigatórias.

Em sua peça, Alencar faz clara alusão ao romance de Stowe, batizando os jovens protagonistas de Jorge e Elisa - homenagem aos jovens escravos fugitivos da Cabana do pai Tomás, George e Elisa.

No comentário sobre a peça, Machado reconhece em Harriet Beecher Stowe a fundadora do que chama de "teatro da escravidão", identifica na Cabana do pai Tomás a matriz de Mãe, peça por meio da qual Alencar levava ao palco esse drama "essencialmente nosso".6

Não foi a única referência de Machado a esse que é considerado o primeiro best-seller produzido nas Américas. Cinco anos mais tarde, em 1865, ao tratar do recém-encenado drama Os cancros sociais, de Maria Ribeiro, o crítico de teatro voltaria a

Machado de Assis, [A Crítica Teatral: José de Alencar: Mãe], texto publicado em 29/3/1860, cf. Obra completa, vol. 3, p. 840. Machado volta a se referir a Mãe em textos de 1866, 1873 e 1879.

Cinco anos mais tarde, Machado voltava ao assunto ao tratar do recém-encenado drama Os cancros sociais, de Maria Ribeiro, autora de outro drama, Gabriela, que causara boa impressão no Machado crítico de teatro. 
reconhecer em Beecher Stowe, referida por ele como "senhora de nomeada internacional", a iniciadora de um tipo de drama fundado no "protesto contra a escravidão"? Dez anos mais tarde, em 1876, na condição de censor do Conservatório Dramático, Machado licenciou uma peça baseada na Cabana do pai Tomás. Talvez por temer a reação do público à peça, deixou para a polícia a responsabilidade de permitir ou não a sua representação. ${ }^{8}$

Para Machado, é inequívoca a primazia de Stowe na escritura dos dramas contra a escravidão, a quem ele sempre se refere com admiração e espanto, por causa da nomeada internacional da escritora, que conseguira algo inédito na literatura das Américas ao inverter pela primeira vez o fluxo da produção literária, até então da Europa em sentido ao Novo Mundo. Tendo em vista o sucesso estrondoso alcançado por Stowe, e em contraste com ele, Machado trata da recepção fria destinada à produção nacional e lamenta as minguadas possibilidades de glória literária no Brasil, chamando a atenção dos seus leitores para o destino inglório dos escritores brasileiros, tomando como elemento de comparação justamente A Cabana do pai Tomás.

Assim, o livro de Stowe explicitava para Machado e outros literatos brasileiros a fragilidade da literatura produzida no Brasil não mais apenas em relação à produção europeia, mas também em relação à literatura produzida no interior da América. A América deixava de ser o espaço literário homogêneo imaginado pelos primeiros românticos, que costumavam referir-se à natureza americana e ao Novo Mundo como um bloco que se diferenciava e contrastava com a Europa e o Velho Mundo, para se tornar um espaço fissurado, à medida que ficavam claras as diferentes potencialidades das partes sul e norte do continente.

Explícitas em Machado, as referências à obra de Stowe estão implícitas em Alencar, como ocorre na peça Mãe. No entanto, as referências ao Pai Tomás aparecerão de modo ainda mais explícito em outros autores-chave do romantismo, como Bernardo Guimarães, em A escrava Isaura - certamente o mais conhecido melodrama da escravidão produzido no Brasil -, e Joaquim Manuel de Macedo, em As vítimas-algozes, título de um conjunto de três novelas publicadas em 1869.

MACHADO DE ASSIS. Crônica publicada em 16 de maio de 1865 no Diário do Rio de Janeiro. In: Coleção Jackson, Chronicas, $2^{\circ}$ volume (1864-1867), 1951, p. 418-9. Grifos meus.

8 A informação foi publicada na Revista Illustrada de 15 de julho de 1876, p. 3. João Roberto Faria, que recolheu todos os escritos de Machado relativos ao teatro, diz ser bem possível que a informação seja verdadeira, embora não conheça esse parecer. Machado foi censor na primeira fase do Conservatório, entre 1862 e 1864, e também na segunda, a partir de 1871, mas infelizmente toda a documentação dessa segunda fase se perdeu.

426 • GUIMARÃES, Hélio de Seixas. Pai Tomás no romantismo brasileiro 
As novelas de Macedo são praticamente panfletos, escritos em plena campanha pela Lei do Ventre Livre, ao que tudo indica a pedido ou pelo menos por sugestão do imperador dom Pedro II, de quem Macedo sempre foi muito próximo. São exemplos perfeitos da instrumentalização política da literatura durante o Segundo Reinado, não escondendo em nenhum momento - como, aliás, ocorre no livro de Stowe - seu objetivo de intervir nos debates sobre os rumos da escravidão no Brasil. Se Flaubert tivesse lido as novelas de Macedo, certamente teria ficado muito mais desagradado do que ficou ao ler A cabana de pai Tomás, tal é a intervenção do autor na apresentação, comentário e enquadramento moral da ação, ainda que com uma postura muito diferente daquela adotada por Stowe.

Desde as páginas iniciais, os objetivos do livro são explícitos, as estratégias de persuasão são muito nítidas, e o argumento principal é muitas vezes reiterado: a escravidão é abominável e precisa ser extinta não porque o escravo seja vítima de uma instituição moralmente condenável, mas porque ela, a escravidão, inevitavelmente transforma o escravo em algoz dos seus senhores, colocando em perigo a ordem, a paz e a integridade da família senhorial.

Em relação a esses expedientes de persuasão, o parâmetro do romance norte-americano, fortemente calcado num discurso humanitário e religioso, ajuda-nos, por contraste, a perceber a outra roupagem, também pesadamente ideológica, com que se revestem as justificativas para o fim da escravidão veiculadas por Macedo. Essas justificativas dizem respeito ao pensamento escravista e antiescravista vigentes no Brasil no momento de intensificação das campanhas emancipacionistas, no final dos anos 1860 e início da década de 1870, quando as discussões sobre os interesses dos proprietários de escravos se sobrepuseram às discussões sobre o destino dos ex-escravos.

No caso de As vítimas-algozes, cujo subtítulo é “Quadros da escravidão" (o que, aliás, remete às "cenas da escravidão" do teatro abolicionista que se inspirou fortemente no livro de Stowe), Macedo deliberadamente produz uma espécie de anti-Pai Tomás. Nas três novelas que compõem o livro, defende o fim da escravidão a partir de princípios diametralmente opostos aos da Cabana do pai Tomás. Não são os valores humanitários e religiosos que estão em jogo, mas a segurança e a permanência mesma do lar patriarcal, com o foco recaindo, em última análise, sobre o corpo da senhora e da Iaiá, ameaçados pelos apetites de homens e mulheres negras.

O livro norte-americano serve de referência não só para as táticas retóricas adotadas pelo narrador, mas também ajuda a explicitar quem é quem na equação entre vítimas e algozes armada pelo título da obra. 
As táticas de persuasão vêm explicitadas já no prólogo, quando o narrador descreve os dois caminhos opostos que poderiam ser tomados para levar "à reprovação profunda que deve inspirar a escravidão": "Um desses caminhos, diz ele, se estende por entre as misérias tristíssimas, e os incalculáveis sofrimentos do escravo, por essa vida de amarguras sem termo, de árido deserto sem um oásis, de inferno perpétuo no mundo negro da escravidão". É o quadro do mal que o senhor, para Macedo ainda sem querer, faz ao escravo.

Esse é o modelo criado pela Cabana do pai Tomás. O outro caminho, prossegue o narrador,

[...] mostra a seus lados os vícios ignóbeis, a perversão, os ódios, os ferozes instintos do escravo, inimigo natural e rancoroso do seu senhor [...] a sífilis moral da escravidão infeccionando a casa, a fazenda, a família dos senhores, e a sua raiva concentrada, mas sempre em conspiração latente atentando contra a fortuna, a vida e a honra dos seus incônscios opressores. É o quadro do mal que o escravo faz de assentado propósito ou às vezes involuntária e irrefletidamente ao senhor. ${ }^{9}$

A estratégia adotada por Macedo explicitamente se opõe à representação do escravo-mártir, encarnado pelo pai Tomás, que encara a tortura física e moral com resignação e fervor religioso, e segue pelo segundo caminho, o da demonização do escravo, tornado algoz pela escravidão, como alerta o autor: "o escravo que vamos expor a vossos olhos é o escravo de nossas casas e de nossas fazendas, o homem que nasceu homem, e que a escravidão tornou peste ou fera". ${ }^{10}$

Já no prólogo nota-se o potencial de violência e ambiguidade contido no livro e também no título. A princípio, as vítimas-algozes referem-se aos escravos. É isso que se supõe, e é isso que o livro até certo ponto confirma. O hífen, que poderia imprimir alguma dinâmica ou dialética à oposição semântica entre vítimas e algozes, acaba por cristalizar senhores e escravos em posições irredutíveis. As vítimas são os senhores, os algozes, os escravos, apartados por um grau de oposição que os coloca quase como entidades dissociadas, como se um nada tivesse a ver com o outro.

O escravo só será definido como vítima ironicamente, em "Lucinda, a mucama", terceira e última história do livro, em que a vitimização do escravo será finalmente

MACEDO, Joaquim Manuel de. As vítimas-algozes - Quadros da escravidão. São Paulo: Scipione; Rio de Janeiro: Fundação Casa de Rui Barbosa, 1991, p. 4 e 5.

10 Idem, p. 5. 
desmoralizada, explicitando o caráter anti-Pai Tomás da obra de Macedo. Isso ocorre justamente na cena em que uma respeitável senhora e sua filha aparecem lendo justamente... A cabana do pai Tomás. Diante do espanto do velho fazendeiro ao encontrar mulher e filha debulhadas em lágrimas diante do livro, intervém o filho, rapaz de ideias progressistas importadas da França e dos Estados Unidos, para explicar ao pai que o romance "concorreu para uma grande revolução social porque encerra grandes verdades". E explica que verdades são essas - "as da privação de todos os direitos, da negação de todos os generosos sentimentos das vítimas, que são os escravos; as da insensibilidade, da crueldade irrefletida, mas real, e do despotismo e da opressão indeclináveis dos senhores".

O diálogo é entreouvido pela mucama Lucinda, que conclui ser ela a vítima.

A vitimização do escravo é a senha para a escrava consumar a vingança contra os senhores, levando à perdição a filha destes, Cândida, menina de onze anos, que a jovem mucama inicia sexualmente, entregando-a a um francês aventureiro.

A visão simpática que o jovem progressista - e ingênuo - Liberato tem do livro de Harriet Beecher Stowe é imediatamente neutralizada pelo curso da narrativa, que insiste no caráter mistificador e no efeito deletério produzido por esse tipo de literatura, recusado desde o início por Macedo, no prólogo ao qual já me referi.

Estão aí alguns exemplos, que certamente poderiam ser multiplicados, da presença que esse romance teve no imaginário dos românticos brasileiros, como modelo e antimodelo para a representação do escravo e da escravidão.

O que procurei mostrar é que, em paralelo às fontes eruditas para a constituição de uma imagem literária para o escravo, caso do Navio negreiro de Heinrich Heine, há o influxo dessas outras fontes literárias talvez menos nobres e menos valorizadas, mas que certamente mobilizaram a imaginação e a sensibilidade dos escritores brasileiros, tornando-se matéria constitutiva das representações do escravo e das cenas da escravidão durante o romantismo no Brasil.

Hélio de Seixas Guimarães é professor de Literatura Brasileira da Universidade de São Paulo e autor de Os leitores de Machado de Assis - o romance machadiano e o público de literatura no século 19 (Nankin/Edusp, 2004). 